\title{
Empreendedorismo corporativo
}

ambiente competitivo em que vivem hoje as empresas Ihes
impõe a necessidade de diferenciação contínua, seja por
meio de produtos ou serviços inovadores. Ocorrequeainovação está diretamente ligada à existência, dentro da organização, de profissionais capazes deempreender e deseguir adiante com suas idéias mesmo quando as circunstâncias são desfavoráveis. 0 artigo destaca a importância dos empreendedores internos no fomento à inovação e à competitividade da empresa.

por Tales Andreassi FGVEAESP

Há quase um século, um jovem de apenas 28 anos de idade escreveu um livro que se tornaria um clássico em nossos dias. Neste livro, ele enuncia um dos temas que hoje mais interessam a executivos e gestores de recursos humanos. Para J oseph Alois Schumpeter, a força motora para as transformações no sistema econômico capitalista era o empreendedor. Para ele, este último tinha a missão principal de inovar, de encontrar novas formas de organizar os fatores de produção existentes, o que resultaria em um novo produto, na exploração de um novo mercado, na 
proposição de uma nova forma de gerir os negócios e assim por diante.

Atual mente, o empreendedorismo reaparece na agenda de preocupações de empresas e gestores de recursos humanos. A idéia é que uma empresa só se torna competitiva no caso de possuir uma força humana criativa e inventiva, ou seja, profissionais capazes de empreender. Este artigo apresenta a discussão de uma das mais recentes abordagens do empreendedorismo nas empresas, a saber, o empreendedorismo corporativo. 0 propósito aqui é apresentar o significado do termo, os principais obstáculos que os gestores devem vencer com o intuito de fomentá-lo e suas vantagens para o estímulo da competitividade e de uma cultura de inovação na empresa. tizado ao longo deste artigo -, pode ser entendido, em linhas gerais, como a capacidade que os funcionários de uma empresa têm para agir como empreendedores.

A pesar de relativamente novo no Brasil, o termo intraempreendedorismo foi cunhado há pelo menos duas décadas pelo norte-americano Guifford Pinchot. Para ele, 0 intra-empreendedor é aquele que assume a responsabilidade, e os desafios correspondentes, pela criação de inovações de qualquer espécie dentro de uma organização.

Mas essa definição pode levar a uma confusão muito comum. Referimo-nos aqui à crença de que o empreendedor é uma espécie de super-homem, ou gênio solitário, capaz de encontrar soluções inéditas a partir do uso de faculdades intelectuais ou intuitivas superiores. $\mathrm{Ou}$

\section{A idéia de empreendedorismo corporativo que} apresentamos aqui pressupõe que a inovação e a atitude empreendedora podem ocorrer em qualquer nível da empresa. Cada funcionário, com suas próprias experiências e recursos, pode inovar e ser empreendedor.

Questão de senti do. Empreendedorismo corporativo pode ser entendido como o processo pelo qual um indivíduo ou um grupo de indivíduos, associados a uma organização existente, criam uma nova organização ou instigam a renovação ou inovação dentro de uma organização existente, na definição de José Carlos Dornelas. Esse conceito, na verdade, abrange dois outros, que são empreendimentos corporativos e intra-empreendedorismo.

0 primeiro, empreendimentos corporativos, referese à capacidade que algumas empresas têm de gerar, a partir de um esforço interno, novas empresas. É o caso, por exemplo, da Origin, que começou a se desenvolver dentro da Philips; da Itautec, braço do Itaú; ou ainda da Gedas, empresa de TI que se originou da Volkswagen. 0 outro conceito, intra-empreendedorismo - que será enfa- ainda podemos pensar na visão folclórica segundo a qual, na empresa, o empreendedorismo é obra ou responsabilidade de poucos iniciados ou então dos altos escalões do poder.

Pelo contrário, a idéia de empreendedorismo corporativo que apresentamos aqui pressupõe que a inovação e a atitude empreendedora podem ocorrer em qualquer nível da empresa. Cada funcionário, com suas próprias experiências e recursos, pode inovar e ser empreendedor. E a história corporativa está repleta de exemplos de profissionais que, independentemente de seu nível, conseguiram revelar forte senso de oportunidade, fina sensibilidade para captar os problemas e desafios de suas empresas, bem como capacidade para improvisar e ser persistente e perseverante no enfrentamento dos obstáculos que surgem pelo caminho.

Obsti nação e perseverança. 0 exemplo do criador do Post-it, Art Fry, químico da 3M, em 1974, é emblemático nesse sentido. Como apresentam Moysés Simantob e Roberta Lippi, Art, ao ter a idéia dos pedaços de papel que colam e descolam, precisou de perseverança para sustentar sua idéia antes que esta tivesse sido reconhecida como válida pela empresa. $\mathrm{A}$ área de produção 
argumentava que o protótipo de uma máquina para fabricar o Post-it levaria no mínimo 6 meses - Art construiu 0 protótipo em um fim de semana em que trabalhou sem descanso. 0 Departamento de Pesquisa de Mercado concluiu que o produto não seria vendável - Art distribuiu amostras e provou que havia demanda para o Post-it.

0 interessante neste caso é que não estamos falando de uma empresa pequena, sem recursos ou sem tradição em inovação. Trata-se da 3M, uma das empresas reconhecidamente mais inovadoras do mundo. E por que foi tão difícil para Art Fry inovar? Porque a existência de uma postura empreendedora na empresa interfere na estrutura de poder, no status quo, na zona de conforto das pessoas e, por isso, é às vezes alvo de intensa resistência. Art Fry, após o Post-it, já não era mais visto como o químico de um dos laboratórios da empresa, mas sim como o responsável por trazer milhões e milhões de dólares para a 3M.

Mas esse tipo de dificuldade que enfrentam os proponentes de novas idéias não é recente, nem muito menos privilégio exclusivo do ambiente corporativo. Um exemplo histórico, produzido por Arthur M. Blank, do Babson College, demonstra que o problema tem raízes muito mais antigas. No século XIX, nas batal has entre navios que existiam na época, praticamente não se utilizavam canhões. Isso porque, com as oscilações provocadas pelo movimento do mar, era praticamente impossível acertar 0 alvo. Em 1889, um oficial na Marinha britânica, chamado Percy Scott, introduziu um mecanismo no suporte dos canhões que se movimentava em fase com o movimento marítimo, de tal modo que o índice de acerto nos alvos aumentou $3.000 \%$.

Em 1900, um jovem tenente norte-americano, William Sims, observando tal mecanismo da Marinha britânica, relatou o que viu a seus superiores hierárquicos. Como não recebeu resposta e era persistente, escreveu para 0 Escritório Central em Washington, que veio a refutar o relatório do tenente Sims. A alegação era de que a idéia havia sido testada e provou ser ineficaz, já que seria impossível arranjar pessoas fortes o suficiente para movimentar os canhões em fase com o movimento marítimo. A equipe que testou a idéia chegou a essa conclusão porque a testou não no mar, onde a oscilação do navio diminui consideravelmente o esforço necessário para movimentar os canhões, mas sim em terra firme!

0 tenente Sims escreveu novamente ao Escritório Central afirmando que a idéia não tinha sido testada propriamente - o que lhe custou uma repreensão por parte do seu superior hierárquico, por ser um "causador de problemas", sendo então "aconsel hado" a cuidar tão-somente dos afazeres que Ihe diziam respeito. 0 tenente Sims, que não desistia fácil, escreveu ao Presidente Roosevelt, que

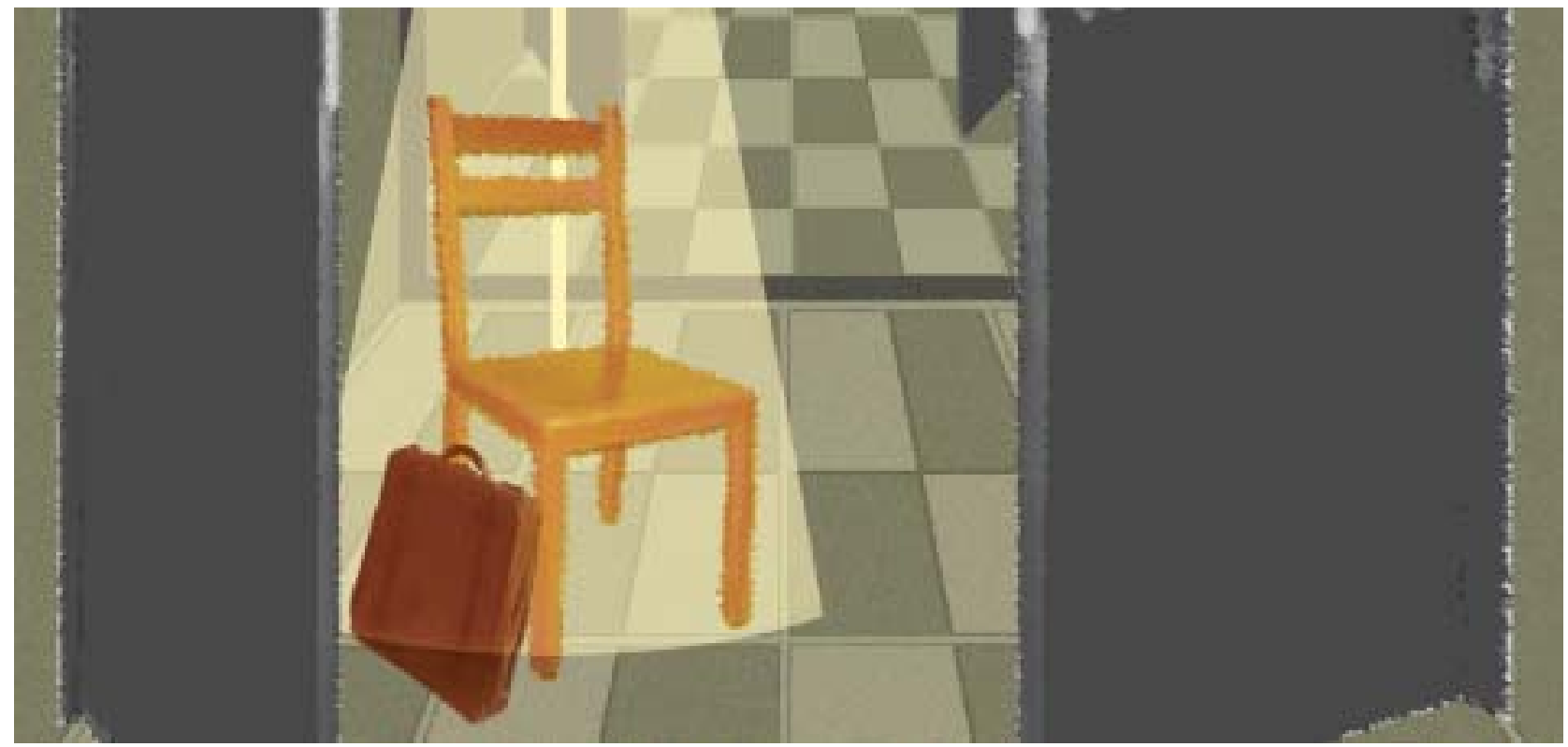


designou um inspetor para ouvir sua história. 0 procedimento foi então aplicado com muito sucesso, e Sims reconhecido e admirado por suas contribuições à Marinha norte-americana.

Ini mi gos domésticos. Esses dois casos ilustram um fato quase inerente à atividade empreended ora: a resistência das pessoas em alterar o status quo ou então em aceitar novas soluções ou formas de pensamento. Na empresa, isso pode ser observado na existência de uma cultura organizacional que não apóia o surgimento de novas idéias, que pune explícita ou implicitamente o erro eque, dessa forma, abafa qualquer possibilidade de surgimento de novos empreendedores. Em uma cultura organizacional com alto nível de distância de poder, por exemplo, os membros no topo da hierarquia de comando certamente terão dificuldade em aceitar que boas idéias possam ser originadas da base. N esses casos, a obstinação e a persistência dos empreendedores podem não ser suficientes para vencer as barreiras da cultura em questão. Vejamos outras barreiras normal mente levantadas contra os empreendedores corporativos.

gra dos $15 \%$ da $3 \mathrm{M}$, de acordo com a qual seus empregados podem aplicar até $15 \%$ do seu tempo no desenvolvimento de projetos de sua escolha, é um bom exemplo de concessão de autonomia aos funcionários - muito embora, devemos mencionar aqui, a própria 3M não a aplique indiscriminadamente, já que está restrita a al gumas áreas e a uma certa seleção nos tipos de projetos.

A autonomia também se estende às questões orçamentárias. Rosabeth Kanter, professora da Harvard Business School, sugere inclusive que os gerentes não precisem prestar conta de uma pequena parte de seu orçamento, a fim de que possam aplicar livremente essa verba em uma pesquisa de mercado para uma idéia nova, um estudo de viabilidade ou algo similar. Dificilmente as pessoas se inclinarão a empreender em empresas onde qual quer solicitação envolve uma gama de assinaturas e autorizações.

U ma outra barreira refere-se à ausência de patrocinadores internos. Aquelas empresas cuja alta direção éadepta de uma regra que poderia ser expressa pela frase "eu ganhei, nós empatamos, vocês perderam" seguramente não irão incentivar o intra-empreendedorismo. 0 patrocinador interno é aquele indivíduo, da al ta cúpula, que se comprometee apóia seus empreendedores, abrindo portas, favorecendo contatos, garantindo recursos para que as idéias sejam testadas e desenvolvidas. E obviamente compartiIha os riscos caso o empreendimento não se concretize.

Por fim, o problema de financiamento de novas idéias representa uma

A intolerância da empresa em relação a riscos e fracassos é outra barreira característica. Imagine um funcionário cujo colega tenha sido demitido porque um projeto que ele propôs acabou fracassando. A probabilidade de esse funcionário propor um projeto inovador é praticamente nula, afinal é muito mais seguro seguir com o que já é aceito e conhecido do que propor novas formas de trabal har ou pensar. Quando muito, nesses casos, o funcionário pode propor apenas al gumas mudanças incrementais, que não chamem a atenção.

Outra barreira refere-se à baixa autonomia para os funcionários desenvolverem seus próprios projetos. A re- barreira igualmente perniciosa. Se a organização puder utilizar parte dos ganhos advindos de novas idéias para financiar outras, cria-se um círculo virtuoso que poderá proporcionar altos retornos no longo prazo. Algumas empresas estão criando fundos especificamente destinados a apoiar novos empreendimentos internos, como veremos no próximo item.

Lições e model os. A Xerox criou um fundo de $30 \mathrm{mi}-$ Ihões de dólares para apoiar novos projetos. Lamentavelmente, tal iniciativa ocorreu tarde, apenas depois de a empresa perder uma série de oportunidades que quase a 
levou a uma situação fatal. Para se ter uma idéia das oportunidades perdidas, os laboratórios da Xerox inventaram, há muitas décadas, o "mouse" e uma rede interna de comunicação que muito se assemelha à intranet de hoje. Muitos desses produtos, por não estarem alinhados às estratégias da empresa, acabaram tendo suas licenças comercializadas para outras empresas. Aqui no Brasil, a Votorantin criou um fundo semelhante. Até o momento propiciou o desenvolvimento de várias empresas ligadas ao grupo, atuando em setores de tecnologia de ponta, como, por exemplo, a Allelyx, a CanaVialis e a Scylla.

Outro exemplo que merece ser citado é o caso da O debrecht e seu sistema de gestão descentralizado, conforme consta do ranking de inovação promovido pela revista Exame, publicado em 23 de junho de 2004. Com $81 \%$ do seu faturamento advindo de obras no exterior, a empresa baseia sua competitividade na atitude empreendedora de seus gerentes responsáveis por sua expansão pelo mundo, os denominados "empresários parceiros". Esses gerentes são muito bem remunerados por suas iniciativas empreendedoras, já que a empresa os premia com mais de $20 \%$ de seu resultado total.

Algumas empresas também desenvolvem o intra-empreendedorismo com idéias simples e eficientes. No programa de trainees da Siemens, todos os participantes devem, ao final, apresentar uma proposta de um novo produto ou processo em um evento no qual está presente a alta direção da empresa. 0 u então a Serasa, cujas áreas possuem dois diretores: um para processos atuais e outro voltado à elaboração de novos projetos. Outro exemplo é o grupo Algar, que possui apenas três níveis hierárquicos e um orçamento construído com base nas sugestões dos empregados.

Vantagens mútuas. Para encerrar, cumpre-nos dizer que empreender internamente traz vantagens tanto para o empreendedor quanto para a empresa. A intensificação da concorrência verificada na última década, aliada ao aumento da exigência dos consumidores e os cada vez menores ciclos de vida dos produtos, têm tornado bastante difícil a introdução de novos produtos no mercado. Nesse contexto, empreender internamente é uma opção certamente valiosa, na medida em que a empresa tem condições de oferecer ao empreendedor toda sua variedade de recursos - humanos, financeiros e técnicos, além de uma marca conhecida - e, dessa forma, criar um ambiente altamente propício à elaboração de novas idéias, seja em forma de novos produtos ou novas soluções para problemas internos ou de seus clientes.

Para a empresa, o intra-empreendedorismo permite que ela aumente sua competitividade perante suas rivais, tanto nos produtos tradicionais quanto em novas áreas de atuação. O utra vantagem é que a inovação acaba se espaIhando para as diversas áreas da organização. Se antes a inovação ficava restrita à área de $P \& D$, hoje a tendência é que ela se mescle com outras áreas - marketing, produção e engenharia - , aumentando sua eficácia e, muito importante, reduzindo o tempo de introdução de novos produtos no mercado.

Desse modo, se uma empresa pretende incrementar seu nível de empreendedorismo interno, vale a pena estar atenta a algumas questões de vital importância. Em primeiro lugar, ao desenvolvimento de uma cultura interna forte de suporte. 0 empreendedor não pode ser deixado sozinho nessa tarefa, pois muitas vezes, como destacado aqui, ele tem de lidar com estruturas estabilizadas e rígidas dentro da organização. Em segundo lugar, os funcionários de todos os níveis têm de sentir, por meio de exemplos de seus gestores, quetodas as idéias são consideradas e real mente levadas adiante. 0 clima de abertura a novas idéias, com proteção para o caso de fracasso ou mesmo inviabilidade, é fundamental para a construção de confiança entre o empreendedor e a empresa. Em terceiro lugar, estudos vêm demonstrando que a remuneração é uma destacada maneira de estimular o surgimento de idéias inovadoras. Embora não haja consenso sobre como essa remuneração deve ser feita, se em grupo ou individualmente, se em dinheiro ou em prêmios, algo parece certo entre diversos especialistas: se a empresa quiser ser competitiva nesses tempos, ela terá de descobrir formas de reconhecimento legítimas para seus empreendedores.

Tales Andreassi

Prof. do Departamento de Administração Geral e Recursos Humanos da FGV-EAESP

Doutor em Administração pela FEA-USP

E-mail: tandeassi@fgvsp.br 